EXTENDED REPORT

\title{
Increased incidence of cardiovascular disease in patients with rheumatoid arthritis: results from a community based study
}

\author{
C Turesson, A Jarenros, L Jacobsson
}

See end of article for authors' affiliations

Correspondence to: $\operatorname{Dr} C$ Turesson, Department of Rheumatology, Malmö University Hospital, 20502 Malmö, Sweden; turesson.carl@mayo.edu

Accepted

16 February 2004

Published online first

29 March 2004

Objective: To investigate the first-ever incidence of acute myocardial infarction and stroke in a community based RA cohort compared with the general population.

Methods: The RA cohort consisted of all patients in a local RA register in Malmö, Sweden $(n=1022)$. The patients were recruited from private and hospital based rheumatology practices, and made up the absolute majority of patients with RA in the city. The general population of Malmö, aged 16 and above, served as controls. From the Swedish National Hospital Discharge Register and the national Swedish Causes of Death Register, information about all first-ever myocardial infarctions and strokes in Malmö residents between July 1997 and December 1999 was retrieved. The age and sex adjusted standardised morbidity ratio (SMR) of the two cohorts was calculated.

Results: Fifty four patients with RA had first-ever myocardial infarctions or stroke during the study period, compared with 3862 subjects in the general population. The age and sex adjusted SMR was 161 (95\% confidence interval (Cl) 121 to 210). The first-ever incidence of cardiovascular disease was increased among female and male patients when studied separately. The increase of cardiovascular events in the RA cohort was mainly due to an excess of myocardial infarctions ( $n=36$; SMR $=176(95 \% \mathrm{Cl} 123$ to 244$)$. Conclusion: Patients with RA in Malmö had an increased first-ever incidence of myocardial infarction or stroke compared with the general population. This confirms that cardiovascular comorbidity is of major importance in RA.

$\mathrm{R}$ heumatoid arthritis (RA) has been associated with increased mortality compared with the general population. ${ }^{1-7}$ The excess mortality has tended to be more pronounced in clinic based studies than in population based surveys, and also higher in studies of RA populations with a longer disease duration than in cohorts with early arthritis. ${ }^{8}$ In some prospective studies of patients with early inflammatory polyarthritis, ${ }^{9}{ }^{10}$ no significantly increased mortality was found, whereas impaired survival was recently demonstrated in rheumatoid factor positive patients in the Norfolk Arthritis Register inception cohort. ${ }^{11}$ A major part of the excess mortality in RA has been attributed to cardiovascular disease (CVD). ${ }^{511-13}$ In recent years, several studies have demonstrated an increased total incidence of fatal and non-fatal cardiovascular events in patients with RA. ${ }^{13-15}$ Available data do not suggest that these associations are due to aggregation of traditional risk factors in patients with RA, ${ }^{14}$ or that they can be explained by adverse effects from antirheumatic treatment. $^{13}$

A correct estimate of the impact of cardiovascular comorbidity in RA requires study of a patient population which is not subject to major selection bias, uses a valid method for the detection of virtually all cardiovascular events in the cohort, and has a relevant comparison group studied using identical methods. Violation of any of these criteria substantially reduces the generalisability of the findings, even in studies of large patient samples.

Using the Swedish National Hospital Discharge Register and Causes of Death Register, we have studied the first-ever incidences of myocardial infarction or stroke in a well defined, community based cohort of patients with RA, compared with the general population in the catchment area.

\section{MATERIALS AND METHODS}

The patients were residents of the city of Malmö, Sweden (population about 260 000). In 1997 a register of all known patients with RA in the city was established. Inclusion was based on a clinical diagnosis of RA by a rheumatologist and fulfilment of the 1987 American College of Rheumatology criteria for RA. ${ }^{16}$ Patients were recruited from the rheumatology outpatient clinic of Malmö University Hospital, which is the only hospital serving the city, and from the four rheumatologists in private practice. ${ }^{17}$ Subsequent surveys using the diagnostic index of primary care centres and questionnaires sent to other physicians in the area indicate that $\geqslant 95 \%$ of all patients with diagnosed RA in the city have been seen by a rheumatologist. ${ }^{17}$ In the 1997 survey, a total of 1022 patients with RA were identified, corresponding to a prevalence of patients with RA currently receiving active care of $0.49 \%$ in the adult population-close to a recent prevalence estimate from Oslo, Norway. ${ }^{18}$

The general population of Malmö, aged 16 years and above, served as the standard population. The age and sex distribution of the control group was based on population statistics from 1998. Data on cardiovascular events were retrieved from the Swedish National Hospital Discharge Register and the Causes of Death Register. ${ }^{19}$ The underlying assumption is that virtually all acute coronary or cerebrovascular events will lead to either admission to hospital or death. These registers are both administered by the Swedish National Board of Health and Welfare. The Hospital Discharge Register is based on reports from local registers, and includes information on age, sex, and place of residence

Abbreviations: AMI, acute myocardial infarction; CVD, cardiovascular disease; RA, rheumatoid arthritis; SMR, standardised morbidity ratio 
Table 1 First-ever cardiovascular events in the RA cohort

\begin{tabular}{|c|c|c|c|c|c|c|}
\hline \multirow[b]{3}{*}{ Age } & \multirow{2}{*}{\multicolumn{2}{|c|}{ Patients }} & \multicolumn{4}{|c|}{ AMls or strokes } \\
\hline & & & \multicolumn{2}{|c|}{ Observed } & \multicolumn{2}{|c|}{ Expected } \\
\hline & Men & Women & Men & Women & Men & Women \\
\hline $15-39$ & 17 & 67 & 0 & 0 & 0 & 0 \\
\hline $40-44$ & 12 & 39 & 0 & 0 & 0 & 0 \\
\hline $45-49$ & 13 & 53 & 0 & 0 & 0.1 & 0.2 \\
\hline $50-54$ & 19 & 70 & 0 & 0 & 0.3 & 0.2 \\
\hline $55-59$ & 35 & 71 & 0 & 0 & 0.7 & 0.5 \\
\hline 60-64 & 30 & 81 & 2 & 4 & 0.9 & 1.0 \\
\hline 65-69 & 41 & 71 & 4 & 4 & 1.9 & 1.9 \\
\hline 70-74 & 30 & 101 & 5 & 5 & 1.7 & 3.0 \\
\hline 75-79 & 38 & 102 & 4 & 7 & 3.2 & 4.8 \\
\hline 80-84 & 21 & 74 & 5 & 8 & 2.5 & 5.7 \\
\hline $85+$ & 10 & 27 & 2 & 4 & 1.8 & 3.6 \\
\hline Total & 266 & 756 & 22 & 32 & 13.0 & 20.6 \\
\hline
\end{tabular}

for each person, as well as the date of admission to hospital and discharge, and discharge diagnoses classified according to the International Classification of Diseases, ninth and tenth revision (ICD-9 and ICD-102021 for each in-patient episode. The proportion of hospital discharges not reported to the register has been estimated to be $1-2 \% .{ }^{19}$ In evaluations of the accuracy of registered diagnoses conducted in 1987 and 1995, 86\% of episodes classified as being due to acute myocardial infarction (AMI) fulfilled predefined criteria for definite AMI, whereas $9 \%$ of patients were considered to have had possible AMI. ${ }^{19}$ The Causes of Death Register is based on compulsory reporting of underlying and contributing causes of death, and contains information on age, sex, place of residence, and date of death. In 1996 the register was estimated to include data on $99.64 \%$ of all deaths. ${ }^{19}$ Previous validation studies of death certification for myocardial infarction have reported confirmation rates of $92-96 \%{ }^{22}$

Data on all hospital episodes with a registered diagnosis of AMI (ICD-10 code I21) or stroke (ICD-10 code I61, I63 or I64), and all deaths due to AMI, ischaemic heart disease (ICD-10 code I23-I25), or stroke for patients in the RA cohort between 1 July 1997 and 31 December 1999 were retrieved from the Hospital Discharge Register and Causes of Death Register. From the same sources, data on hospital episodes and deaths due to these causes during the same time were identified for residents of Malmö. First episodes were noted in both groups. In addition, data on AMI or stroke between

Table 2 First-ever incidence of cardiovascular events among patients with RA compared with controls

\begin{tabular}{lll}
\hline Outcome & SMR & $95 \% \mathrm{Cl}$ \\
\hline AMl or stroke & 161 & 121 to 210 \\
All & 155 & 106 to 219 \\
Women & 169 & 106 to 257 \\
Men & & \\
AMl & 176 & 123 to 244 \\
All & 180 & 103 to 256 \\
Women & 172 & 96 to 283 \\
Men & & \\
Stroke & 121 & 74 to 186 \\
All & 112 & 58 to 195 \\
Women & 137 & 59 to 270 \\
Men &
\end{tabular}

1 January 1987 and 30 June 1997 (ICD-9 codes 410, 431, 434, and 436 for the Hospital Discharge Register) were retrieved, and people with a registered cardiovascular event during that time were excluded. People without a record of AMI or stroke between 1987 and 1997 were assumed not to have had cardiovascular events before inclusion in the study (1 July 1997).The starting date for this analysis of 1 January 1987 was based on the establishment of the Hospital Discharge Register.

To determine age and sex-specific event rates, the male and female subgroup of patients and controls were stratified into 15 age groups (that is, 145 year periods: 15-19 year olds, 2024 year olds, etc, and a $\geqslant 85$ year old group (table 1 ). Based on indirect standardisation to the Malmö general population, the expected number of events for each group in the RA cohort was estimated. Age adjusted standardised morbidity ratios (SMRs) with 95\% confidence intervals were calculated for each sex separately for AMI, stroke, and AMI or stroke combined, and the age and sex adjusted SMRs were calculated for each of these outcomes.

\section{RESULTS}

The RA cohort consisted of 1022 patients (756 women and 266 men). Table 1 shows the age and sex distribution of the patients. The standard population consisted of 207846 adult residents of Malmö, Sweden (110 003 women and 97843 men). In the RA cohort, 54 patients had first-ever cardiovascular events during the follow up (1 July 1997 to 31 December 1999), compared with 3862 in the control group. The age and sex adjusted SMR for first-ever AMI or stroke was 161 (95\% confidence interval (95\% CI) 121 to 210 ). Cardiovascular morbidity was increased for women with RA $(S M R=155 ; 95 \%$ CI 106 to 219$)$ and for men $(S M R=169$; 95\% CI 106 to 257). Thirty six patients in the RA cohort and 2419 patients in the control group had first-ever AMI, corresponding to an SMR of 176 (95\% CI 123 to 244). Twenty patients with RA had first-ever stroke, compared with 1840 people in the control group. There was a trend towards an increased first-ever incidence of stroke in the RA cohort, but the difference was not significant ( SMR $=121$; 95\% CI 74 to 186). Among the patients with RA, three patients had haemorrhagic stroke and 17 had non-haemorrhagic or non-specified stroke. The magnitude of the increased comorbidity from AMI, and the smaller difference for stroke, in the RA cohort was similar among men and women (table 2). Thus, the increased incidence of cardiovascular events in the RA cohort was mainly due to a higher than expected number of AMIs for both sexes. 


\section{DISCUSSION}

In this community based cohort of patients with RA, the first-ever incidence of cardiovascular events was significantly increased compared with the general population. This was mainly due to a higher than expected number of myocardial infarctions. Cardiovascular comorbidity was increased to a similar extent in men and in women.

Accumulating evidence indicates that the cardiovascular mortality and morbidity associated with RA is due to disease specific factors, rather than to ascertainment bias or to confounders. Among the Pima Indians of Arizona, USA, who have one of the highest prevalences of RA in the world, ${ }^{23}$ the presence of swollen joints was found to be a predictor of cardiovascular mortality in the general population. This effect was independent of traditional risk factors such as high blood pressure, smoking, and high serum cholesterol. ${ }^{24}$ Overall, the most important predictors of mortality in RA are measures of disability such as the Disability Index of the Health Assessment Questionnaire, ${ }^{25} 26$ and extra-articular disease manifestations. ${ }^{27-29}$ This indicates that factors associated with disease severity may play a part in the pathogenesis of comorbid conditions in patients with RA. It has also been suggested that extensive inflammation and high disease activity predicts cardiovascular events and mortality in RA, ${ }^{30}$ and mortality from coronary artery disease may be particularly increased in patients with severe extra-articular disease. $^{27}$ Data from observational studies suggest that cardiovascular mortality is reduced in patients treated with methotrexate compared with subjects who have not received such treatment. ${ }^{31}$ Successful antirheumatic pharmacotherapy may thus have a beneficial effect on RA associated vascular disease.

The pathogenic mechanisms involved in macrovascular pathology in RA are beginning to be determined. Recent reports indicate that carotid artery intima-media thickness, a measure of early atherosclerosis, ${ }^{32}$ may be increased in patients with RA, ${ }^{33}{ }^{34}$ and that it correlates with markers of systemic inflammation in patients with RA as well as in subjects without the disease. ${ }^{35}$ Increased arterial stiffness ${ }^{36}$ and increased circulating prothrombotic markers ${ }^{37}$ may also contribute to the risk of cardiovascular events in RA. Shared immunological disease mechanisms in systemic autoimmune disorders and CVD, such as clonally expanded CD $4^{+} \mathrm{CD} 28^{-} \mathrm{T}$ cells, ${ }^{38}{ }^{39}$ systemic endothelial activation, ${ }^{40}{ }^{41}$ and circulating immune complexes, ${ }^{42}$ may be involved in the development of cardiovascular comorbidity in such patients.

The significantly increased incidence of AMI, but not of stroke, in our cohort is in accordance with other studies. ${ }^{15}$ Possibly, RA associated vascular abnormalities specifically predispose to coronary artery disease, and not to cerebrovascular events.

The main limitations of this study concern the ascertainment of cardiovascular events, which could not be directly controlled by the investigators. Validation studies have demonstrated a high level of accuracy for the Hospital Discharge Register, ${ }^{19}$ and the Causes of Death Register, ${ }^{22}$ but misclassification is still likely to occur in some cases. ${ }^{43}$ There is, however, no intuitive reason to believe that this should have a different effect in the RA cohort than in the general population. Random misclassification would only decrease the likelihood of detecting true differences between the subgroups.

The available data did not enable us to control for differences in lifestyle factors between the RA cohort and the standard population. Smoking ${ }^{44}$ and obesity ${ }^{45}$ are associated with RA, and this may account for part of the increase in CVD morbidity in this group, although previous surveys do not indicate that this is the major explanation. ${ }^{35}$ Furthermore, additional possible confounders, such as potentially deleterious effects of corticosteroids, and lipid abnormalities, could not be evaluated in this study.

The major strength of the study is the community based approach, and the fact that the RA cohort and the control group are truly representative of the population in the area. The results of this study are thus unlikely to be explained by selection bias. The method of investigating well defined cohorts and comparison groups using national registers may be a promising tool for the long term observational studies of the effect of therapeutic interventions among patients with RA and other rheumatic diseases. Retrospective analysis of a 10 year period before the study allowed us to exclude patients with CVD events during this interval, and we were thus likely to identify patients with first-ever myocardial infarction or stroke.

In conclusion, using national registers to detect in-patient episodes and fatal events, we have demonstrated an increased first-ever incidence of cardiovascular morbidity in a community based RA cohort compared with the general population in the corresponding area. This indicates that RA associated CVD is a substantial health problem in the community. Heightened awareness of the risk of CVD, as well as adequate preventive strategies, are of major importance in the management of patients with RA.

\section{ACKNOWLEDGEMENTS}

We thank the following rheumatologists who contributed patients to the Malmö RA cohort: Christina Book, Åsa Hagstam, Eva Juran, Ylva Lindroth, Rolf Manthorpe, Lida Marsal, Gabriella Olsson, Elke Theander, and Pia Vannerberg-Lindell. In addition, we thank Dr Gunnar Engström, Dr Bo Hedblad, and Dr Patrik Tydén for useful discussions on the study.

This study was supported by the Swedish Rheumatism Association.

\section{Authors' affiliations}

C Turesson, A Jarenros, L Jacobsson, Department of Rheumatology, Malmö University Hospital, Lund University, Sweden

\section{REFERENCES}

1 Cobb S, Anderson F, Baver W. Length of life and cause of death in rheumatoid arthritis. N Eng J Med 1953;249:553-6.

2 Allebeck P, Ahlbom A, Allander E. Increased mortality among persons with rheumatoid arthritis, but where RA does not appear on death certificate. Eleven-year follow-up of an epidemiological study. Scand J Rheumatol 1981;10:301-6.

3 Pincus T, Callahan LF, Sale WG, Brooks AL, Payne LE, Vaughn WK. Severe functional declines, work disability, and increased mortality in seventy-five rheumatoid arthritis patients studied over nine years. Arthritis Rheum 1984;27:864-72.

4 Reilly PA, Cosh JA, Maddison PJ, Rasker JJ, Silman AJ. Mortality and survival in rheumatoid arthritis: a 25 year prospective study of 100 patients. Ann Rheum Dis 1990:49:363-9.

5 Jacobsson LT, Knowler WC, Pillemer S, Hanson RL, Pettitt DJ, Nelson RG, et al. Rheumatoid arthritis and mortality. A longitudinal study in Pima Indians. Arthritis Rheum 1993;36:1045-53.

6 Wolfe F, Mitchell DM, Sibley JT, Fries JF, Bloch DA, Williams CA, et al. The mortality of rheumatoid arthritis. Arthritis Rheum 1994;37:481-94.

7 Heliovaara M, Aho K, Knekt P, Aromaa A, Maatela J, Reunanen A. Rheumatoid factor, chronic arthritis and mortality. Ann Rheum Dis 1995:54:811-14.

8 Ward MM. Recent improvements in survival in patients with rheumatoid arthritis: better outcomes or different study design? Arthritis Rheum $2001 ; 44: 1467-9$

9 Lindqvist E, Eberhardt K. Mortality in rheumatoid arthritis patients with disease onset in the 1980s. Ann Rheum Dis 1999;58:11-14.

10 Kroot EJ, van Leeuwen MA, van Rijswijk MH, Prevoo ML, 't Hof MA, van de Putte LB, et al. No increased mortality in patients with rheumatoid arthritis: up to 10 years of follow up from disease onset. Ann Rheum Dis 2000;59:954-8.

11 Goodson NJ, Wiles NJ, Lunt M, Barrett EM, Silman AJ, Symmons DP. Mortality in early inflammatory polyarthritis: cardiovascular mortality is increased in seropositive patients. Arthritis Rheum 2002;46:2010-19.

12 Myllykangas-Luosujarvi R, Aho K, Kautiainen H, Isomaki H. Cardiovascular mortality in women with rheumatoid arthritis. J Rheumatol 1995;22:1065-7.

13 Wallberg-Jonsson S, Ohman ML, Dahlqvist SR. Cardiovascular morbidity and mortality in patients with seropositive rheumatoid arthritis in Northern Sweden. J Rheumatol 1997;24:445-51.

14 del Rincon ID, Williams K, Stern MP, Freeman GL, Escalante A. High incidence of cardiovascular events in a rheumatoid arthritis cohort not 
explained by traditional cardiac risk factors. Arthritis Rheum 2001;44:2737-45.

15 Solomon DH, Karlson EW, Rimm EB, Cannuscio CC, Mandl LA, Manson JE, et al. Cardiovascular morbidity and mortality in women diagnosed with rheumatoid arthritis. Circulation 2003;107:1303-7.

16 Arnett FC, Edworthy SM, Bloch DA, McShane DJ, Fries JF, Cooper NS, et al. The American Rheumatism Association 1987 revised criteria for the classification of rheumatoid arthritis. Arthritis Rheum 1988:31:315-24.

17 Jacobsson L, Lindroth Y, Marsal L, Tejer L. [The Malmo model for private and public rheumatological outpatient care. Cooperation makes it possible to introduce disease modifying treatment quickly]. Lakartidningen 2001;98:4710-16.

18 Kvien TK, Glennas A, Knudsrod OG, Smedstad LM, Mowinckel P, Forre O. The prevalence and severity of rheumatoid arthritis in Oslo. Results from a county register and a population survey. Scand I Rheumatol 1997; 26:412-18.

19 The Center for Epidemiology. The Swedish National Board of Health and Welfare. http://www.sos.se/epc (accessed 18 May 2004).

20 World Health Organisation. International classification of diseases: manual of the international statistical classification of diseases, injuries, and causes of death: based on the recommendations of the ninth revision conference, 1975, and adopted by the twenty-ninth World Health Assembly. 9th ed. Geneva: World Health Organization, 1977.

21 World Health Organisation. International statistical classifications of diseases and related health problems. 10th ed. Geneva: World Health Organization, 1994.

22 Sundman L, Jakobsson S, Nystrom L, Rosen M. A validation of cause of death certification for ischaemic heart disease in two Swedish municipalities. Scand J Prim Health Care 1988;6:205-11.

23 del Puente A, Knowler WC, Pettitt DJ, Bennett PH. High incidence and prevalence of rheumatoid arthritis in Pima Indians. Am J Epidemiol 1989;129:1170-8.

24 Jacobsson LT, Turesson C, Hanson RL, Pillemer S, Sievers ML, Pettitt DJ, et al. Joint swelling as a predictor of death from cardiovascular disease in a population study of Pima Indians. Arthritis Rheum 2001;44:1170-6.

25 Pincus T, Brooks RH, Callahan LF. Prediction of long-term mortality in patients with rheumatoid arthritis according to simple questionnaire and joint count measures. Ann Intern Med 1994; 120:26-34.

26 Wolfe F, Michaud K, Gefeller O, Choi HK. Predicting mortality in patients with rheumatoid arthritis. Arthritis Rheum 2003;48:1530-42.

27 Turesson C, Jacobsson L, Bergstrom U. Extra-articular rheumatoid arthritis: prevalence and mortality. Rheumatology (Oxford) 1999:38:668-74.

28 Turesson C, O'Fallon WM, Crowson CS, Gabriel SE, Matteson EL. Occurrence of extraarticular disease manifestations is associated with excess mortality in a community based cohort of patients with rheumatoid arthritis. J Rheumatol 2002;29:62-7.

29 Gabriel SE, Crowson CS, Kremers HM, Doran MF, Turesson C, O'Fallon WM, et al. Survival in rheumatoid arthritis: a population-based analysis of trends over 40 years. Arthritis Rheum 2003;48:54-58.

30 Wallberg-Jonsson S, Johansson H, Ohman ML, Rantapaa-Dahlqvist S. Extent of inflammation predicts cardiovascular disease and overall mortality in seropositive rheumatoid arthritis. A retrospective cohort study from disease onset. J Rheumatol 1999;26:2562-71.

31 Choi HK, Hernan MA, Seeger JD, Robins JM, Wolfe F. Methotrexate and mortality in patients with rheumatoid arthritis: a prospective study. Lancet 2002;359:1173-7.

32 Persson J, Formgren J, Israelsson B, Berglund G. Ultrasound-determined intima-media thickness and atherosclerosis. Direct and indirect validation. Arterioscler Thromb 1994; 14:261-4.

33 Park YB, Ahn CW, Choi HK, Lee SH, In BH, Lee HC, et al. Atherosclerosis in rheumatoid arthritis: morphologic evidence obtained by carotid ultrasound. Arthritis Rheum 2002;46:1714-19.

34 Kumeda Y, Inaba M, Goto H, Nagata M, Henmi Y, Furumitsu Y, et al. Increased thickness of the arterial intima-media detected by ultrasonography in patients with rheumatoid arthritis. Arthritis Rheum 2002;46:1489-97.

35 Del Rincon I, Williams K, Stern MP, Freeman GL, O'Leary DH, Escalante A. Association between carotid atherosclerosis and markers of inflammation in rheumatoid arthritis patients and healthy subjects. Arthritis Rheum 2003:48: 1833-40

36 Klocke R, Cockcroft JR, Taylor GJ, Hall IR, Blake DR. Arterial stiffness and central blood pressure, as determined by pulse wave analysis, in rheumatoid arthritis. Ann Rheum Dis 2003;62:414-18.

37 McEntegart A, Capell HA, Creran D, Rumley A, Woodward M, Lowe GD. Cardiovascular risk factors, including thrombotic variables, in a population with rheumatoid arthritis. Rheumatology (Oxford) 2001;40:640-4.

38 Liuzzo G, Goronzy JJ, Yang H, Kopecky SL, Holmes DR, Frye RL, et al. Monoclonal T-cell proliferation and plaque instability in acute coronary syndromes. Circulation 2000;101:2883-8.

39 Liuzzo G, Vallejo AN, Kopecky SL, Frye RL, Holmes DR, Goronzy JJ, et al. Molecular fingerprint of interferon-gamma signaling in unstable angina. Circulation 2001;103:1509-14.

40 Turesson C, Englund P, Jacobsson LT, Sturfelt G, Truedsson L, Nennesmo I, et al. Increased endothelial expression of HLA-DQ and interleukin lalpha in extra-articular rheumatoid arthritis. Results from immunohistochemical studies of skeletal muscle. Rheumatology (Oxford) 2001;40:1346-54.

41 Mahon NG, Madden BP, Caforio AL, Elliott PM, Haven AJ, Keogh BE, et al. Immunohistologic evidence of myocardial disease in apparently healthy relatives of patients with dilated cardiomyopathy. J Am Coll Cardiol 2002;39:455-62.

42 Mustafa A, Nityanand S, Berglund L, Lithell H, Lefvert AK. Circulating immune complexes in 50-year-old men as a strong and independent risk factor for myocardial infarction. Circulation 2000; 102:2576-81.

43 Johansson LA, Westerling R. Comparing Swedish hospital discharge records with death certificates: implications for mortality statistics. Int I Epidemiol 2000;29:495-502.

44 Silman AJ, Newman J, MacGregor AJ. Cigarette smoking increases the risk of rheumatoid arthritis. Results from a nationwide study of disease-discordant twins. Arthritis Rheum 1996:39:732-5.

45 Symmons DP, Bankhead CR, Harrison BJ, Brennan P, Barrett EM, Scott DG, et al. Blood transfusion, smoking, and obesity as risk factors for the development of rheumatoid arthritis: results from a primary care-based incident case-control study in Norfolk, England. Arthritis Rheum 1997;40:1955-61. 